\title{
Impact of anxiety on sedative medication dosage in patients undergoing esophagogastroduodenoscopy
}

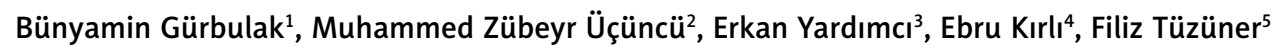 \\ ${ }^{1}$ Department of General Surgery, T.C. Health Sciences University, Istanbul Training and Research Hospital, Istanbul, Turkey \\ ${ }^{2}$ Healt Sciences Institute, T.C. Istanbul Gelişim University, Istanbul, Turkey \\ ${ }^{3}$ Department of General Surgery, Bezmialem Vakıf University, Istanbul, Turkey \\ ${ }^{4}$ Department of Psychiatry, Arnavutköy State Hospital, Istanbul, Turkey \\ ${ }^{5}$ Department of Anesthesiology and Reanimation, Arnavutköy State Hospital, Istanbul, Turkey
}

Videosurgery Miniinv 2018; 13 (2): 192-198 DOI: https://doi.org/10.5114/wiitm.2018.73594

\begin{abstract}
Introduction: Esophagogastroduodenoscopy (EGD) is a diagnostic method used in the investigation of upper gastrointestinal system diseases. A high level of anxiety of patients who undergo EGD increases the duration of the procedure and the sedation and analgesic requirements. Sedation is used to increase patient comfort and tolerance by reducing the anxiety and pain associated with endoscopic procedures.

Aim: In this study, the effect of anxiety scores on medication doses was investigated in patients who underwent EGD under sedation.

Material and methods: A psychiatrist, an endoscopist and an anesthesiologist conducted a prospective observational study blindly to investigate the effect of pre-procedural (before EGD) anxiety level on medication doses for sedation. Patients were divided into two groups, with and without additional medication doses.

Results: The study included 210 consecutive patients who underwent EGD under sedation. The average STAI-S score was 40.28 and the average STAI-T score was 40.18. There was no relationship between anxiety scores and gender $(p=0.058, p=0.869)$. Statistically significant results were obtained for anxiety scores with additional sedation dosing ( $p$ < 0.05). It was observed that an additional dose of medication was affected by age, body mass index and anxiety scores $(p<0.005)$. Patients who were young, had a low body mass index and had high anxiety scores had significantly higher additional dose requirements.

Conclusions: The medications used for sedation during EGD may be inadequate or an additional dose of medication may be needed for patients who have higher anxiety scores, younger age, and lower body mass index.
\end{abstract}

Key words: anxiety, endoscopy, conscious sedation.

\section{Introduction}

Esophagogastroduodenoscopy (EGD) is an invasive diagnostic method used in the investigation and follow-up of upper gastrointestinal system diseases. Therapeutic procedures can also be performed simultaneously [1, 2].

Sedation is the induction of depressed consciousness and is dependent on the drug dose [3].
In the past, sedation often was not performed with regard for the patients' condition for the procedure of EGD, but in recent times sedation has been preferred for the comfort of the patient and the endoscopist. Sedation is used to increase patient comfort and tolerance by reducing the anxiety and pain associated with endoscopic procedures, the gag reflex, nausea, vomiting, dizziness, and to increase the ef-

\section{Address for correspondence}

Bünyamin Gürbulak MD, Department of General Surgery, T.C. Health Sciences University, Istanbul Training and Research Hospital,

34098 Istanbul, Turkey, phone: +90 5554883025, fax: +90 2124366258, e-mail: bgurbulak@gmail.com 
fectiveness of the procedure by reducing the risk of injury during endoscopy [3-5]. However, there may be severe cardiopulmonary adverse events due to sedation regimens [6].

The anxiety of the patient may be due to inadequate information about the procedure, a feeling of discomfort and perceived pain. High anxiety of the patient may not only increase dissatisfaction, but also increase the duration of the procedure, the risk of complications, and the sedation and analgesic requirements $[7,8]$.

Sedative drugs do not usually provide analgesia when they cause hypnosis and amnesia, so analgesic drugs are added along with sedative drugs [9].

\section{Aim}

In our study, the effect of anxiety scores on drug dose was investigated in patients who underwent EGD under sedation.

\section{Material and methods}

We planned a prospective, observational and triple-blind study to investigate the effect of pre-procedural (before EGD) anxiety level on drug doses for sedation.

Patients who underwent diagnostic EGD for upper gastrointestinal system complaints between January 2016 and June 2016 in the Arnavutköy State Hospital Endoscopy unit were included in this study. Detailed information was given about the sedation and EGD procedure and written informed consent was obtained from all patients included in the study. Patients under 18 years old and above 65 years old, patients who did not want sedation, who were sensitive or allergic to drugs used for sedation, who had a previous EGD or other sedative procedure or sedation-related complication history, psychiatric disorder, drug addiction, patients with a history of gastrointestinal system (GIS) surgery or with an American Society of Anesthesiologists (ASA) score of 3 or above were not included in the study.

Demographic data were recorded, such as age, gender, educational status, marital status, medications, co-morbid disease and past medical history. Medications and doses used during EGD, additional dose requirements, vital findings and endoscopy data were recorded prospectively. Patients were divided into two groups, with and without additional doses.

\section{Evaluation of anxiety and sedation}

Anxiety scores were assessed by the psychiatrist with the Spielberger State-Trait Anxiety Inventory (STAI-S, STAI-T) before the procedure, but these scores were not reported to the endoscopist and the anesthesiologist. The STAI scale consists of two parts. STAI-S evaluates the state of anxiety due to the intensity of the affected emotional event over time. STAI-T evaluates more stable anxiety, which is stable over time and is not affected by the intensity of momentary emotional states [10]. Spielberger's STAI scale was translated into the Turkish language and its reliability and validity were confirmed by Oner and Le Compte [11].

After the patient was evaluated by the psychiatrist before the procedure, the anxiety that could be caused by waiting was avoided by the patient being brought directly to undergo the EGD procedure without waiting in the endoscopy unit. The psychiatrist, the endoscopist and the anesthesiologist conducted a prospective blind observational study.

\section{Sedation protocol}

Sedation for all procedures was performed by the same anesthesiologist and all patients were monitored during the procedure and given $2 \mathrm{l} / \mathrm{min}$ of oxygen if necessary. Sedation was initiated by administering $1 \mathrm{mg} / \mathrm{kg}$ propofol in addition to $0.05 \mathrm{mg} / \mathrm{kg}$ midazolam to each patient, and repeated doses of 10 or $20 \mathrm{mg}$ of propofol were administered to continue the sedation at baseline if necessary for continued sedation. The decision was made based on whether the patient had adequate sedation for the procedure and the additional dose requirement was determined by the anesthesiologist and the endoscopist according to the patient's compliance and the Observer's Assessment of Alertness/Sedation Scale (OAA/S). At the beginning and during the procedure, the patient was evaluated with OAA/S every $1 \mathrm{~min}$ [12]. The procedure was completed by providing a moderate sedation level in the range of OAA/S 2-4, and the patients were divided into two groups, with and without additional doses.

For this study, local ethics committee approval was obtained from the Haseki Training and Research Hospital affiliated with T.C. Health Sciences University.

\section{Statistical analysis}

Descriptive statistical methods including mean, standard deviation, frequency and ratio were used 
when the data were evaluated. The distribution of variables was analyzed by the Kolmogorov-Smirnov test. The independent samples $t$-test and Mann-Whitney $U$ test were used in the analysis of quantitative data, and the $\chi^{2}$ test was used in the analysis of qualitative data. Spearman correlation analysis and log regression analysis were used for multivariate analysis. The program SPSS 22.0 was used when analyzing the data.

\section{Results}

The study included 210 consecutive patients who underwent EGD under sedation. Of these patients, 79 (37.6\%) were female and 131 (62.4\%) were male. The mean age of the participants was $40.51 \pm 11.53$ years. The mean body mass index (BMI) of the patients studied was $27.80 \pm 6.2 \mathrm{~kg} / \mathrm{m}^{2}$. Four people had a BMI less than 18 and 150 people had a BMI of $25 \mathrm{~kg} / \mathrm{m}^{2}$ or more (Table I).

When EGD findings were examined, gastritis was found in 165 patients, ulcers in the antrum and bulbus in 32 patients, alkaline reflux gastritis

Table I. Body-mass index

\begin{tabular}{|lcc|}
\hline BMI $\left[\mathrm{kg} / \mathrm{m}^{2}\right]$ & $N$ & $\%$ \\
\hline$<18$ & 4 & 1.9 \\
\hline $18-25$ & 66 & 31.4 \\
\hline $25-29$ & 65 & 30.9 \\
\hline$>29$ & 75 & 35.8 \\
\hline
\end{tabular}

in 11 patients and stomach cancer in 2 patients. Forty-one patients had cardio-esophageal sphincter insufficiency while 12 patients had hiatal hernia. An incomplete pyloric ring was detected in 86 patients. The most common finding of EGD was gastritis (78.5\%) and all endoscopic findings are shown in Figure 1. Complications related to endoscopy and sedation did not develop in the patients included in this study.

When the anxiety score was examined, the average STAI-S score was 40.28 and the average STAI-T score was 40.18 . There was no relationship between state and trait anxiety scores and gender ( $p=0.058$, $p=0.869)$. The mean propofol dose was 94.83 $\pm 30.79 \mathrm{mg}$ (min: 50, max: $210 \mathrm{mg}$ ). Sixty-seven (31\%) patients needed additional medication doses for an adequate sedation level during the procedure. A statistically significant relationship was observed between state and trait anxiety scores and additional medication doses for sedation $(p<0.05)$ (Table II).

When correlation analysis of the patients with additional medication doses was examined, it was found that the additional dose of medication was affected by age, BMI, and state and trait anxiety score $(p<0.005)$.

Patients who were young, had a low BMI and had high anxiety scores had significantly higher additional dose requirements. There was no significant relationship between the need for an additional dose for adequate sedation and $\operatorname{sex}(p=0.85)$. If the state of anxiety score was above 40 , the risk of
A

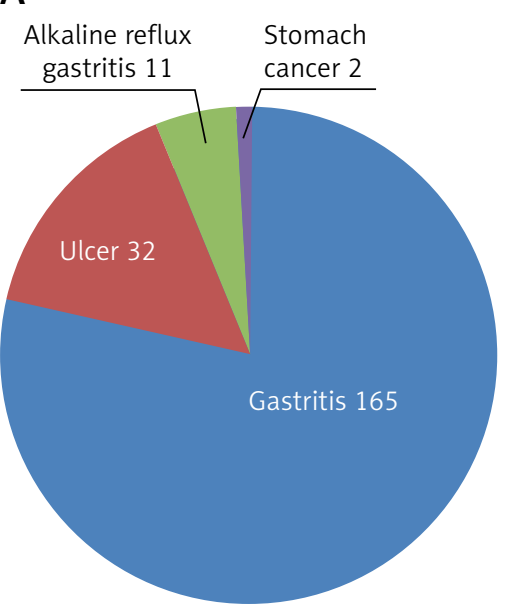

B

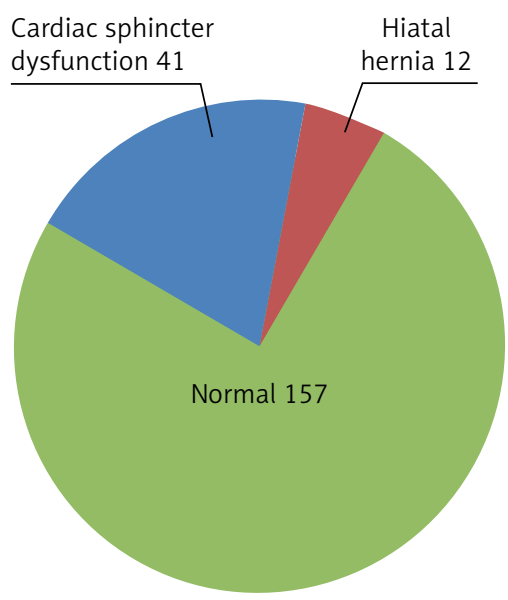

C

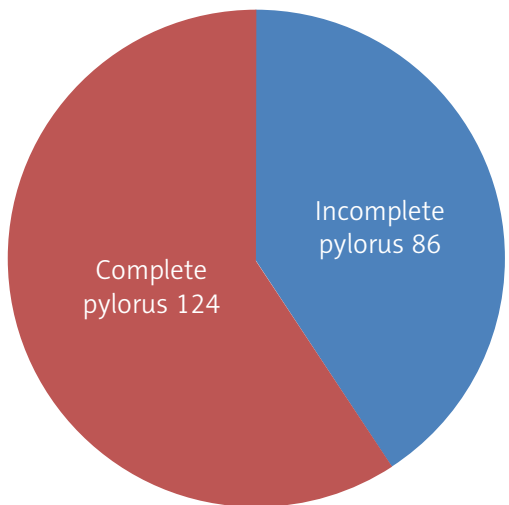

Figure 1. Esophagogastroduodenoscopy findings: A - endoscopic diagnosis, B - status of the cardiac sphincter, $\mathbf{C}$ - status of the pylorus 
Table II. Comparison of groups with and without additional doses

\begin{tabular}{|lccc|}
\hline Parameter & $\begin{array}{c}\text { Additional dosing } \\
(n=67)\end{array}$ & $\begin{array}{c}\text { No additional dose } \\
(n=143)\end{array}$ & $P$-value \\
\hline BMI $\left[\mathrm{kg} / \mathrm{m}^{2}\right]$ & $25.03 \pm 5.54$ & $28.41 \pm 5.05$ & 0.002 \\
\hline Age [years] & $34.16 \pm 10.74$ & $43.75 \pm 10.92$ & $<0.001$ \\
\hline Anxiety level: & & & 0.001 \\
\hline STAl-S & $44.05 \pm 8.61$ & $38.51 \pm 8.49$ & 0.005 \\
\hline STAI-T & $42.86 \pm 6.87$ & $38.92 \pm 6.8$ & \\
\hline
\end{tabular}

Table III. Estimated risk analysis

\begin{tabular}{|lcccc|}
\hline Variable & Value & Lower & Upper & $P$-value \\
\hline State anxiety $>40$ & 5.081 & 2.112 & 12.224 & $<0.001$ \\
\hline Trait anxiety $>40$ & 4.118 & 1.720 & 9.859 & 0.001 \\
\hline
\end{tabular}

an additional dose of medication increased five-fold, and if the trait of anxiety score was above 40, the risk of an additional dose of medication increased four-fold (Table III).

\section{Discussion}

Improvements in endoscopy devices and an increase in the number of endoscopy centers have led to an increase in sedation practices for patient and endoscopist comfort, as well as an increase in the number of EGDs used to evaluate upper GIS complaints [13, 14].

The main purpose of this study was to determine the conditions that might be associated with pre-procedural anxiety levels in patients with EGD for upper gastrointestinal complaints and to determine whether there is a relationship between drug dosages for sedation and anxiety, which has not been studied extensively in the literature.

The feeling of discomfort and fear caused by sensorial factors such as pain and nausea due to endoscopic procedures, the cancer suspicion that can be detected as a result of the procedure, and the anxiety caused by the biopsy such as doctor fear, physician and assistant health staff attitudes and behaviors, as well as situations related to inadequate information about sedation, increase the anxiety level [15].

Anxiety has been shown to have a negative effect on postoperative recovery, pain and duration of hospital stay [16].
Various sedation and analgesia methods are used for EGD, and the optimal drug is still controversial. For sedation, benzodiazepines (especially midazolam), opioids and propofol are used. Recently, propofol has been preferred in sedation, but there are also debates about which drugs should be used and who should be sedating [17]. The main argument in this regard is that the practice of sedation by an anesthesiologist increases the cost. In a prospective study on this point, it was shown that trained endoscopy nurses and endoscopists can successfully sedate with propofol, which also reduces costs [18]. There are also studies showing an increased risk of aspiration and pneumonia due to sedation performed by anesthesiologists [19]. Vargo et al. have shown that anesthesiologists do not reduce the risk of sedation-related serious side effects. However, it was emphasized that ASA 4-5 patients should be sedated by an anesthesiologist [20].

The amount of medication to be given for sedation is determined by the procedure and factors related to the patient. Patient-related factors are age, BMI, medications used, co-morbid disease of the patient, pre-procedural anxiety status, pain tolerance, and whether the patient has previously undergone sedation. Factors related to the procedure include the feeling of discomfort related to the procedure, the condition in which the patient must remain relatively motionless during the procedure, and the duration of the procedure [3, 21, 22].

How sedation should be applied for endoscopy is still being discussed. The most appropriate protocol 
for the patient should be decided according to the patient's risk factors and the procedure to be performed [23, 24]. Combinations of drugs to be administered for sedation can reduce the side effects that a single medicine can produce [25].

Patient age, gender, ASA score and BMI, as well as anxiety level, affect the dose of medications. In a study conducted by Chung et al. they found no relationship between anxiety scores and sedation requirements in patients undergoing colonoscopy [26]. The study by Kil et al. demonstrated the opposite of this [27]. In another study it was stated that anxiety is an important factor in procedures requiring sedation at a lower level and that the level of pre-procedural anxiety and the need for medication for deep sedation would increase [28].

We observed that high anxiety scores also increased the amount of additional medication doses for sedation.

However, there are different opinions regarding sedation for colonoscopy. Some studies have emphasized that sedation should not be given, especially during colonoscopy $[29,30]$, but there are also studies suggesting that sedation prevents patients from having anxiety and avoiding colonoscopy [31]. It is reported that complications such as perforation of the colon due to the procedure may increase although anxiety and pain under deep sedation are minimized [32, 33].

It has been shown that during the colonoscopy the anxiolytic effect of music reduces pain and anxiety, which in turn reduces the dose of medication used for sedation [34-36].

In another study, it was shown that informative video material before the colonoscopy had no effect on tolerance and anxiety [37].

In another study, a significant decrease in STAI scores was detected with pre-procedural temporal and sensorial information and detailed informed consent [38].

In the literature, it is stated that the level of anxiety of the patient decreases with oral explanation, information brochures/booklets, written informed consent and video materials, and patient satisfaction increases $[39,40]$.

Patients should be informed about the procedure (waiting during the pre-procedural period in the appropriate waiting room in which patients who have undergone the procedure are not seen, not eating before the procedure, informing about the procedure and the time after the procedure), sensorially (feeling of disturbing taste sensation due to spray, pain, nausea and gagging reflex) and temporally (how long the procedure will take and what it will be like after the procedure), which is effective in reducing anxiety in patients with high anxiety [7, 15].

In our study, we thought that the waiting period could increase the level of anxiety and the need for medication, so the patients were allowed to undergo the procedure without waiting.

In our study, we observed that patients with high anxiety had an increased need for medication and additional doses of medication, so we recommend that adequate temporal, sensorial and procedural information should be provided before starting the procedure.

The disadvantage of this study was that the Visual Analogue Scale (VAS) score was not compared with the STAI score. However, pain in the EGD procedure is less common than in a colonoscopy, so pain assessment was not included in the study.

\section{Conclusions}

We found that medications used for sedation during EGD may be inadequate or an additional dose of medication may be needed for patients who have higher anxiety scores, younger age and lower BMI. Anxiety scores can be determined before the procedure, and for those patients who have a higher anxiety score sedation should be performed with the assistance of an anesthesiologist. For definitive results, there is a need for randomized controlled trials involving a larger number of patients.

\section{Conflict of interest}

The authors declare no conflict of interest.

\section{References}

1. Beg S, Ragunath K, Wyman A, et al. Quality standards in upper gastrointestinal endoscopy: a position statement of the British Society of Gastroenterology (BSG) and Association of Upper Gastrointestinal Surgeons of Great Britain and Ireland (AUGIS). Gut 2017; 66: 1886-99.

2. Choi KS, Suh M. Screening for gastric cancer: the usefullness of endoscopy. Clin Endosc 2014; 47: 490-6.

3. Cohen LB, Delegge MH, Aisenberg J, et al. AGA Institute review of endoscopic sedation. Gastroenterology 2007; 133: 675-701.

4. Tandon M, Pandey VK, Dubey GK, et al. Addition of sub-anaesthetic dose of ketamine reduces gag reflex during propofol based sedation for upper gastrointestinal endoscopy: a pro- 
spective randomised double-blind study. Indian J Anaesth 2014; 58: 436-41

5. Ozel AM, Oncü K, Yazgan Y, et al. Comparison of the effects of intravenous midazolam alone and in combination with meperidine on hemodynamic and respiratory responses and on patient compliance during upper gastrointestinal endoscopy: a randomized, double-blind trial. Turk J Gastroenterol 2008; 19 8-13.

6. Sieg A, Hachmoeller-Eisenbach U, Eisenbach T. Prospective evaluation of complications in outpatient GI endoscopy: a survey among German gastroenterologists. Gastrointest Endosc 2001; 53: 620-7.

7. van Zuuren FJ, Grypdonck M, Crevits E, et al. The effect of an information brochure on patients undergoing gastrointestinal endoscopy: a randomized controlled study. Patient Educ Couns 2006; 64: 173-82.

8. Felley C, Perneger TV, Goulet I, et al. Combined written and oral information prior to gastrointestinal endoscopy compared with oral information alone: a randomized trial. BMC Gastroenterol 2008; 8: 22

9. Karan SB, Bailey PL. Update and review of moderate and deep sedation. Gastrointest Endosc Clin N Am 2004; 14: 289-312.

10. Spielberger $C$. The State-Trait Anxiety Inventory (Form Y). Palo Alto, California: Mind Garden, 1983.

11. Oner N, Le Compte A. Durumluk-Sürekli Kaygı Envanteri El kitabı. İstanbul: Boğaziçi Yayınları, 1985.

12. Chernik DA, Gillings D, Laine $H$, et al. Validity and reliability of the Observer's Assessment of Alertness/Sedation Scale: study with intravenous midazolam. J Clin Psychopharmacol 1990; 10: 244-51.

13. Khiani VS, Soulos P, Gancayco J, et al. Anesthesiologist involvement in screening colonoscopy: temporal trends and cost implications in the medicare population. Clin Gastroenterol Hepatol 2012; 10: 58-64.

14. Inadomi JM, Gunnarsson CL, Rizzo JA, et al. Projected increased growth rate of anesthesia professional-delivered sedation for colonoscopy and EGD in the United States: 2009 to 2015. Gastrointest Endosc 2010; 72: 580-6.

15. Maguire D, Walsh JC, Little CL. The effect of information and behavioural training on endoscopy patients' clinical outcomes. Patient Educ Couns 2004; 54: 61-5.

16. Kiecolt-Glaser JK, Page GG, Marucha PT, et al. Psychological influences on surgical recovery. Perspectives from psychoneuroimmunology. Am Psychol 1998; 53: 1209-18.

17. Rex DK, Deenadayalu VP, Eid E, et al. Endoscopist-directed administration of propofol: a worldwide safety experience. Gastroenterology 2009; 137: 1229-37.

18. Yusoff IF, Raymond G, Sahai AV. Endoscopist administered propofol for upper-GI EUS is safe and effective: a prospective study in 500 patients. Gastrointest Endosc 2004; 60: 356-60.

19. Cooper GS, Kou TD, Rex DK. Complications following colonoscopy with anesthesia assistance: a population-based analysis. JAMA Intern Med 2013; 173: 551-6.

20. Vargo JJ, Niklewski PJ, Williams JL, et al. Patient safety during sedation by anesthesia professionals during routine upper endoscopy and colonoscopy: an analysis of 1.38 million procedures. Gastrointest Endosc 2017; 85: 101-8.
21. American Association for Study of Liver Diseases; American College of Gastroenterology; American Gastroenterological Association Institute, et al. Multisociety sedation curriculum for gastrointestinal endoscopy. Gastrointest Endosc 2012; 76: e1-25.

22. Standards of Practice Committee of the American Society for Gastrointestinal Endoscopy, Lichtenstein DR, Jagannath S, Baron TH, et al. Sedation and anesthesia in GI endoscopy. Gastrointest Endosc 2008; 68: 815-26.

23. Faigel DO, Baron TH, Goldstein JL, et al. Guidelines for the use of deep sedation and anesthesia for GI endoscopy. Gastrointest Endosc 2002; 56: 613-17.

24. Lee H, Kim JH. Superiority of split dose midazolam as conscious sedation for outpatient colonoscopy. World I Gastroenterol 2009; 15: 3783-87.

25. Waring JP, Baron TH, Hirota WK, et al. Guidelines for conscious sedation and monitoring during gastrointestinal endoscopy. Gastrointest Endosc 2003; 58: 317-22.

26. Chung KC, Juang SE, Lee KC, et al. The effect of pre procedure anxiety on sedative requirements for sedation during colonoscopy. Anaesthesia 2013; 68: 253-9.

27. Kil HK, Kim WO, Chung WY, et al. Preoperative anxiety and pain sensitivity are independent predictors of propofol and sevoflurane requirements in general anaesthesia. $\mathrm{Br}$ J Anaesth 2012; 108: 119-25.

28. Osborn TM, Sandler NA. The effects of preoperative anxiety on intravenous sedation. Anesthesia Progress 2004; 51: 46-51.

29. Madan A, Minocha A. Who is willing to undergo endoscopy without sedation: patients, nurses, or the physicians? South Med I 2004; 97: 800-5.

30. Early DS, Saifuddin T, Johnson JC, et al. Patient attitudes toward undergoing colonoscopy without sedation. Am J Gastroenterol 1999; 94: 1862-5.

31. Parker D. Human responses to colonoscopy. Gastroenterol Nurs 1992; 189.

32. Adeyemo A, Bannazadeh M, Riggs T, et al. Does sedation type affect colonoscopy perforation rates? Dis Colon Rectum 2014; 57: 110-4.

33. Korman LY, Haddad NG, Metz DC, et al. Effect of propofol anesthesia on force application during colonoscopy. Gastrointest Endosc 2014; 79: 657-62.

34. Lee DW, Chan KW, Poon CM, et al. Relaxation music decreases the dose of patient-controlled sedation during colonoscopy: a prospective randomized controlled trial. Gastrointest Endosc 2002; 55: 33-6.

35. Dubois JM, Bartter T, Pratter MR. Music improves patient comfort level during outpatient bronchoscopy. Chest 1995; 108: 129-30.

36. Corah NL, Gale EN, Pace LF, et al. Relaxation and musical programming as means of reducing psychological stress during dental procedures. J Am Dent Assoc 1981; 103: 232-4.

37. Bytzer P, Lindeberg B. Impact of an information video before colonoscopy on patient satisfaction and anxiety - a randomized trial. Endoscopy 2007; 39: 710-4.

38. Kutlutürkan S, Görgülü U, Fesci H, et al. The effects of providing pre-gastrointestinal endoscopy written educational material on patients' anxiety: a randomised controlled trial. Int I Nurs Stud 2010; 47: 1066-73. 
39. Callaghan P, Chan HC. The effect of videotaped or written information on Chinese gastroscopy patients' clinical outcomes. Patient Educ Couns 2001; 42: 225-30.

40. Kim HW, Jung DH, Youn YH, et al. Written educational material relieves anxiety after endoscopic biopsy: a prospective randomized controlled study. Korean J Gastroenterol 2016; 67: 92-7.

Received: 26.11.2017, accepted: 28.01.2018. 